\title{
MANHAJ TAFSIR AL-MIZAN FI TAFSIR AL-QUR'AN KARYA MUHAMMAD HUSAIN TABATABA'I
}

\author{
Ahmad Fauzan \\ Progam Pascasarjana Prodi Aqidah dan Filsafat Islam UIN Sunan Kalijaga Yogyakarta \\ Email: Afauzan757@gmail.com
}

Received: 27-10-2018, Accepted: 28-10-2018, Published: 30-10-2018

\begin{abstract}
Theologically-normative, the truth of the Qur'an is absolute, because it is derived from the Essence of the True and Absolute. However, after the absolute is understood, and included in the disk of human thought (mufassir), it changes to the relative truth, because it is impossible that the relative (ie human thought) will be able to capture one hundred percent of the Absolute. Therefore, even though the Al-Qur'an text is single, in reality the results of the understanding and interpretation of the text will experience diversity, sometimes even there seems to be a contradiction between one another. As in the book of the interpretation of al-Mizan by Tabataba'i's work which is interpreted by explaining the verse with the verse, history. Then he also explained verses with various approaches, such as philosophy (falsafy), sociological (ijtima'i), historical (tarikhy), scientific ('ilmy), scientific and ethical (' ilmy wa akhlaqy), scientific and philosophical ('ilmy wa falsafy), and rational and qur'ani ('aqly wa qur'any).

Keywords: Interpretation, Tabataba'i, al-Mizan.
\end{abstract}

\begin{abstract}
Abstrak
Secara teologis-normatif, kebenaran al-Qur'an adalah mutlak, sebab ia berasal dari Dzat Yang Maha Benar dan Mutlak. Namun demikian, setelah yang mutlak itu dipahami, dan dimasukkan dalam disket pemikiran manusia (mufassir), ia berubah menjadi relatif kebenarannya, karena tidak mungkin yang relatif itu (yaitu pemikiran manusia) akan mampu menangkap seratus persen dari yang Maha Mutlak tersebut. Oleh sebab itu, meskipun teks alQur'an itu tunggal, namun pada kenyataannya hasil dari pemahaman dan penafsiran terhadap teks itu akan mengalami keragaman, bahkan kadang tampak ada kontradiksi antara satu dengan lainnya. Seperti dalam kitab tafsir al-Mizan karya Tabataba'i yang penafsirannya dengan cara menjelaskan ayat dengan ayat, riwayat. Kemudian beliau juga menjelaskan ayat dengan berbagai pendekatan, seperti filsafat (falsafy), sosiologis (ijtima'i), historis (tarikhy), ilmiah ('ilmy), ilmiah dan etika ('ilmy wa akhlaqy), ilmiah dan filosofis ('ilmy wa falsafy), dan rassional dan qur'ani ( 'aqly wa qur'any).
\end{abstract}

Kata Kunci : Tafsir, Tabataba'i, al-Mizan. 


\section{A. Latar Belakang Masalah}

Muhammad Husain Tabataba'i merupakan salah satu ulama yang ahli dalam bidang tafsir dengan nama Tafsir al-Mizan fi Tafsir al-Qur'an. Dengan latar belakang ajaran Syi'ah semasa menutut ilmu, maka sedikit banyak beliau memasukkan dan membawa ajaran Syi'ah ke dalam tafsirnya. ${ }^{1}$ Kitab ini tidak hanya tersebar di kalangan muslim Syi'ah, namun juga tersebar luas di kalangan muslim Sunni. Di antara faktor penyebab diterimanya tafsir ini di kalangan muslim Sunni adalah karena tafsir ini mengutamakan penggunaan sumber bil al-ma'sur sebagai sumber penafsirannya. ${ }^{2}$

Dalam sejarah tafsir al-Qur'an, di antaranya dibuktikan dengan banyaknya produk kitab tafsir, menunjukkan bahwa tafsir juga merupakan sebuah usaha untuk mengadaptasikan teks al-Qur'an ke dalam situasi kontemporer seorang mufassir. Hal ini menunjukkan bahwa tafsir terhadap al-Qur'an dilakukan bukan sekedar untuk memenuhi

${ }^{1}$ Khairunnas Jamal. (2011). Pengaruh Pemikiran Husain Thabathaba'i dalam Tafsir al-Mishbah", Jurnal Ushuluddin, Vol. XVII, No. 2, hlm. 204

2 Irhas. (2016). Penerapan Tafsir alQur'an bi al-Qur'an (Studi Atas Kitab Tafsir al-Mizan fi Tafsir al-Qur'an Karya Muhammad Husain al-Thabathaba'i). Jurnal Ushuluddin, Vol. 24, No. 2, hlm. 150. kebutuhan teoritis untuk memahami pesan-pesan al-Qur'an, tapi juga dilakukan untuk memenuhi kebutuhan praktis yang besar untuk mendapatkan petunjuk kitab suci yang akan diamalkan dalam kehidupan sehari-hari. ${ }^{3}$

Dalam tafsir Syiah memiliki ciriciri yang utama dalam penafsiran dan penekanannya yang menjadikan cabang tafsir ini memiliki khas serta beberapa karakteristik yang menonjol dalam perkembangannya. Salah satu prinsip penting dalam tafsir Syiah adalah bahwa al-Qur'an harus terlihat selalu memiliki relevansinya atau memungkinkan penerapannya bagi orang-orang dan keadaan-keadaan tertentu. Prinsip lainnya menyiratkan kegandaan makna seperti muhkam dan mutasyabih, nasikh dan mansukh, dhahir dan batin, dan ta'wil dan tanzil. ${ }^{4}$

Dalam tulisan ini akan di bahas mengenai biografi Tabataba'i, profil dan manhaj penafsiran kitab tafsir al-Mizan, dan kelebihan dan kekurangan kitab tafsir al-Mizan, dengan harapan agar wacana tulisan ini nantinya dapat

\footnotetext{
${ }^{3}$ Waryono Abdul Ghafur. (2008). Millah
} Ibrahim dalam Al-Mizan fi tafsir al-Qur'an. Yogyakarta: Bidang Akademik, hlm. 31.

4 Mahmud Ayub. (1991). Qur'an dan Para Penafsirnya. Jakarta: Pustaka Firdaus, hlm. 51. 
bermanfaat bagi penulis sendiri khususnya dan bagi para pembaca pada umumnya.

\section{B. Gambaran Umum Metode dan Corak Penafsiran Syi'ah}

Gambaran umum terkait metode dan corak penafsiran Syi'ah, penulis membatasi pembicaraan pada cabang Syi'ah yang terpenting saja, yakni Syi'ah Zaidiyah dan Syi'ah Imamiah (Syi'ah Itsna Asyariyah dan Syi'ah Ismailiyah). Kedua kelompok Syi'ah ini masih memiliki pengikut dan pendukung sampai saat ini. Kaum Syi'ah Itsna Asyariyah sekalipun menyeleweng, namun memiliki banyak tokoh-tokoh pengarang tafsir yang kitab-kitabnya memenuhi perpustakaan Islam. Begitu juga dengan Syi'ah Zaidiyah, mereka juga memiliki tokoh-tokoh tafsir yang kitab-kitabnya telah diakui oleh Ahlu Sunnah, seperti kitab tafsir karya Imam Syaukani yaitu Fathul Qadir. Metode penafsiran yang dilakukan oleh Syi'ah Itsna Asyariyah adalah selalu berupaya sekuat tenaga untuk menyesuaikan ayatayat Allah s.w.t. dengan prinsip-prinsip mereka. Umpamanya saja tentang masalah imamah, mereka tidak hanya mencukupkan diri dengan perkataan yang meyakinkan serta nash-nash dari Rasulullah s.a.w. mengenai keimaman
Ali dan imam-imam selanjutnya, tetapi mereka juga berusaha menundukkan ayat-ayat Allah s.w.t. kepada pendapat tentang wajibnya keimaman Ali setelah Rasulullah s.a.w. secara langsung tanpa terputus. ${ }^{5}$

Sedangkan pandangan mereka mengenai pengertian tafsir bil-ma'tsur adalah keterangan-keterangan yang terdapat dalam al-Qur'an itu sendiri, mengenai ayat-ayatnya, apa-apa yang dikutip dari Rasulullah s.a.w., serta apa-apa yang dikutip dari imam-imam dua belas. Menurut mereka, ucapanucapan para Imam yang ma'shum termasuk dalam kategori sunnah. Ucapan-ucapan para imam dianggap sebagai hujjah dan tak ubahnya seperti perkataan Nabi s.a.w., karena mereka berbicara dengan bimbingan dari Rasulullah s.a.w. sebagaimana Nabi s.a.w. berbicara (menyampaikan agama) dan dibimbing oleh Allah s.w.t. ${ }^{6}$ Adapun metode penafsiran yang digunakan oleh Syi'ah Ismailiyah di dalam menafsirkan al-Qur'an adalah dengan menyatakan bahwa, al-Qur'an

5 Mahmud Basuni Faudah. (1987). Tafsir- tafsir Al- Quran Pengenalan dengan Metodologi Tafsir. Bandung: Pustaka, hlm. 135.

${ }^{6}$ Mahmud Basuni Faudah. (1987) Tafsirtafsir Al- Quran Pengenalan dengan Metodologi Tafsir. Bandung: Pustaka, hlm. 136. 
itu mempunyai dua makna, yaitu makna lahir dan makna batin. Sedangkan yang dikehendaki adalah makna batinnya, karena yang lahir itu sudah cukup dimaklumi dari ketentuan bahasa. Adapun nisbat antara yang batin dan yang lahir itu adalah seperti isi dengan kulitnya. ${ }^{7}$

Mayoritas Islam Syi'ah di Iran Modern dan di dunia pada umumnya adalah Syi'ah Itsna 'Asyariyah atau Syi'ah Imamiyah yang dikenal dengan Syi'ah Isma'iliyyah, yakni Syi'ah yang mendapat ajaran keagamaan dan inspirasi spiritual dari 12 Imam. Tabataba'i adalah penganut Syiah 12 Imam ini. ${ }^{8}$ Prinsip-prinsip dasar Syi'ah ini meliputi 5 hal, yakni tauhid (penegasan akan keEsaan Allah), nubuwwah (yang berahir dengan Nabi Muhammad s.a.w. dan al-Qur'an sebagai Risalah Allah yang terakhir), ma'ad (kehidupan di akhirat), 'adl (keadilan Allah), dan imamah. ${ }^{9}$

Sebagaimana diketahui bahwa Syi'ah merupakan sebuah golongan

\footnotetext{
${ }^{7}$ Mahmud Basuni Faudah, Tafsir- tafsir Al- Quran, hlm. 221.

${ }^{8}$ Muhammad Husain Tabataba'i. (1998). al-Mizan fi Tafsir al-Qur'an. Lebanon: Beirut, hlm. 4.

${ }^{9}$ Waryono Abdul Ghafur. (2008). Millah Ibrahim dalam Al-Mizan fi tafsir al-Qur'an. Yogyakarta: Bidang Akademik, hlm. 75.
}

yang sangat mengagungkan sahabat Ali bin Abi Thalib. Sampai-sampai kecintaannya ini telah melebihi batas, yakni menyatakan bahwa Ali lebih mulia dari Nabi sendiri. Sehingga keyakinan dan akidah mereka ini telah menghantarkannya pada perbedaan yang ketara dibandingkan pada kelompok Sunni maupun yang lainnya, diantaranya dalam penafsiran alQur'an. Dalam menafsirkan al-Qur'an, kebanyakan dari Syi'ah bertujuan untuk melegitimasi akidah dan keyakinan mereka. Sehingga dari sini secara umum corak penafsiran Syi'ah terhadap al-Qur'an dapat digolongkan sebagai corak madzhabi.

\section{Biografi Muhammad Husein Tabataba'i}

Tabataba'i adalah nama yang populer bagi penulis kitab al-Mizan fi Tafsir al-Qur'an. Nama lengkapnya adalah Muhammad Husain Tabataba'i. ${ }^{10}$ Penisbatan Tabataba'i ini adalah merujuk pada kakeknya, yakni Ibrahim Tabataba'i bin Ismail alDibaj. ${ }^{11}$ Nasab beliau dari Jalur bapak sampai pada Imam Hasan al-Mujtaba, sedangkan dari jalur ibu sampai pada

\footnotetext{
10 Muhammad Husain Tabataba'i, alMizan fi Tafsir al-Qur'an, hlm. A

11 Muhammad Husain Tabataba'i, alMizan fi Tafsir al-Qur'an, hlm. A.
} 
saudaranya Imam Hasan, yakni Imam Husain, oleh karena itu, beliau memiliki nisbat nama lengkap Muhammad Husain al-Hasani al-Husaini alTabataba'i. $^{12}$ Beliau lahir pada akhir $1321 \mathrm{H}$, tepatnya pada 29 Dzulhijjah $1321 \mathrm{H}$. atau bertepatan dengan 1892 M. di desa Shadegan, Propinsi Tibriz atau Tabriz (propinsi yang pernah dijadikan sebagai ibu kota pada Dinasti Safawi). Beliau lahir dari keluarga ulama keturunan Nabi yang selama 14 generasi telah menghasilkan ulamaulama yang terkemuka di Tibriz, termaksud Tabataba'i sendiri. ${ }^{13}$

Tabataba'i mengawali rihlah ilmiahnya sejak usia dini di Tibriz di atas naungan keluarganya dan juga pemuka kaum di daerahnya. Kemudian pada tahun $1343 \mathrm{H}$, beliau hijrah untuk rihlah ilmiah ke Najaf di salah satu Universitas Syi'ah di Iran selama kurang lebih 10 tahun. $^{14}$ Di kota ini, beliau mempelajari berbagai fans ilmu pengetahuan yang wajib bagi para pencari ilmu. Di kota ini pula beliau

\footnotetext{
12 Muhammad Husain Tabataba'i. (2006). Tafsir al-Bayan fi al-Muwafaqah baina al-Hadis wa al-Qur'an. Lebanon: Beirut, hlm. 21.

13 Muhammad Husain Tabataba'i, alMizan fi Tafsir al-Qur'an, hlm. Ba.

14 Muhammad Husain Tabataba'i, alMizan fi Tafsir al-Qur'an, hlm. Ja
}

menjalani latihan spiritual dan mulai memasuki dimensi batin Islam yang dalam Syi'ah dinamakan dengan irfan. ${ }^{15}$

Dalam fans ilmu fiqh dan alushul, beliau belajar kepada Syekh Muhammad Husain al-Na'ini dan Syekh Muhammad Husain al-Kambani, sedang fans ilmu falsafah beliau belajar kepada Sayyid Husain al-Badakubi. Beliau juga belajar ilmu riyadhoh kepada Sayyid Abi Qasim al-Khunisari, dan fans ilmu akhlaq kepada Syekh Mirza Ali al-Qadhi. ${ }^{16}$ Tidak tercatat ada guru lain di luar Syi'ah yang membimbing keilmuan beliau. Dalam perjalanan keilmuannya, Tabataba'i tidak pernah jauh dari negerinya Iran. Kota-kota di Iran seperti Qum, Tibriz dan Teheran adalah di antara kota yang turut membentuk karakter keilmuannya hingga memiliki pandangan yang berpengaruh kepada masyarakat Syi'ah di Iran. ${ }^{17}$

Tabataba'i mewakili dari golongan ulama dan intelektual dari

${ }^{15}$ Khairunnas Jamal. (2011). "Pengaruh Pemikiran Husain Thabathaba'i dalam Tafsir al-Mishbah", Jurnal Ushuluddin Vol. XVII, No. 2, hlm. 205.

16 Muhammad Husain Tabataba'i, alMizan fi Tafsir al-Qur'an, hlm. Ba.

${ }^{17}$ Khairunnas Jamal. (2011). "Pengaruh Pemikiran Husain Thabathaba'i dalam Tafsir al-Mishbah", Jurnal Ushuluddin Vol. XVII, No. 2, hlm. 20. 
ulama Syi'ah yang punya pengaruh besar. Beliau telah menggabungkan perhatian dalam bidang fikih dan tafsir al-Qur'an dengan filsafat, juga teosofi dengan tasawuf, dan orang yang mewakili satu penafsiran tentang Syi'ah yang lebih universal. Dalam golongan tradisional, Tabataba'i mempunyai penguasaan yang sangat menonjol baik mengenai pengetahuanpengetahuan syari'at maupun lahiriyah dan sekaligus beliau seorang filosof muslim tradisional terkemuka. ${ }^{18}$ Beliau wafat pada waktu subuh hari Ahad tanggal 18 Muharram pada tahun 1402 H, dan dimakamkan di daerah Qum. ${ }^{19}$

\section{Karya-karyanya}

Telah diketahui bahwa Tabataba'i merupakan tipe ulama atau intelektual Syiah kontemporer yang mengusai berbagai cabang ilmu. Penguasaannya terhadap berbagai cabang ilmu tersebut terlihat dari berbagai karya-karya yang ditulisnya yang di antaranya sebagaimana tercamtum dalam muqodimah al-Mizan

\footnotetext{
18 Muhammad Husein Tabataba'i. (1993)). Islam Syi'ah; Asal Usul dan Perkembangannya. Jakarta: PT. Temprint, hlm. 19.

19 Muhammad Husain Tabataba'i. (2006)). Tafsir al-Bayan fi al-Muwafaqah baina al-Hadis wa al-Qur'an. Lebanon: Beirut, hlm. 24.
}

fi tafsir al-Qur'an adalah: ${ }^{20}$ Ushul alFalsafah, Bidayah al-Hikmah fi alFalsafah, Ta'liqat 'ala Kitab al-Asfar fi al-Falsafah li al-Filoshof, Ta'liqat 'ala Kitab Ushul al-Kafiy, Risalah fi alAsma' wa al-Shifat, Risalah fi alI'tibarat, Risalah al-I'jaz, Risalah fi alAf'al, Risalah fi al-Insan ba'd alDunya, Risalah fi al-Insan fi al-Dunya, Rislah fi al-Insan Qabl al-Dunya, Risalah fi al-Burhan, Risalah fi alTahlil, Risalah fi al-Tarkib, Risalah fi al-Dzat, Risalah fi 'Ilmu al-Imam, Risalah fi al-Quwwah wa al-Fi'l, Risalah fi al-Mustaqat, Risalah fi alMughalatah, Risalah fi al-Nubuat wa al-Manamat, Risalah fi Nadmmi alHukm, Risalah fi al-Wahy, Risalah fi al-Wasait, Risalah fi al-Wilayah, Risalah fi al-Islam, Al-Qur'an fi alIslam, Al-Mar'ah fi al-Islam, Mandzumah fi Qawaid al-Khath alFarizy, dan Al-Mizan fi Tafsir alQur'an.

\section{E. Pandangan Tabataba'i Terhadap Tafsir}

Sebagaimana kaum Muslim umumnya, Tabataba'i menyakini bahwa al-Qur'an adalah sebuah kitab

20 Muhammad Husain Tabataba'i. (1998). al-Mizan fi Tafsir al-Qur'an. Lebanon: Beirut, hlm. 
abadi untuk semua masa. Hukumnya berlaku untuk semua manusia. Mengingat masa berlakunya yang transhistoris, al-Qur'an selalu relevan untuk setiap masa dengan tidak dibatasi oleh ruang dan waktu. Menurut beliau, seluruh ayat al-Qur'an harus dapat dipahami oleh semua orang. Dapat dipahaminya seluruh al-Qur'an karena ia menggunakan bahasa manusia yang sederhana dan jelas dengan syarat manusia menggunakan penalarannya. ${ }^{21}$ Pandangannya mengenai al-Qur'an yang dapat dipahami oleh semua orang, menurut beliau tidak bertentangan dengan posisi Rasul dan Imam Ahli Bait yang sebelumnya diberi kewenangan mutlak untuk menjelaskan al-Qur'an. $^{22}$

Pengertian tafsir sebagaimana yang beliau kemukakan dalam muqadimah, adalah menjelaskan ayatayat al-Qur'an serta membuka tujuan dan sasaran yang dikehendaki oleh alQur'an. ${ }^{23}$ Menurut beliau, seluruh ayat al-Qur'an dapat dipahami oleh semua

\footnotetext{
21 Waryono Abdul Ghafur. Millah Ibrahim dalam Al-Mizan. hlm. 80-85.

22 Muhammad Husain Tabataba'i. (1998). al-Mizan fi Tafsir al-Qur'an. Lebanon: Beirut, hlm. $\mathrm{Ha}$

23 Muhammad Husain Tabataba'i. (1998). al-Mizan fi Tafsir al-Qur'an. Lebanon: Beirut, hlm. 7.
}

manusia. Karena, dalam pandangan Tabataba'i, al-Qur'an dengan jelas menyifati dirinya dengan sifat-sifat seperti cahaya, petunjuk dan penjelas. Dengan sifat-sifatnya ini, setiap manusia dapat menentukan jalan untuk mengetahui maksud al-Qur'an. Hal ini sebagaimana dijelaskan oleh beliau bahwa jalan yang mardhiyyah (memberikan kepuasan atau yang menyenangkan) di dalam menafsirkan al-Qur'an adalah dengan cara menafsirkan al-Qur'an dengan alQur'an serta mendatangkan hal yang membenarkan dari apa yang dikehendaki oleh ayat-ayat al-Qur'an, sebagaimana firman Allah dalam QS. Al-Nahl ayat $89:^{24}$

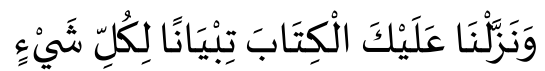

Menurut pentahqiq Muhammad Hadi menyatakan bahwa kitab tafsir alMizan tafsir yang mengumpulkan semua himpunan pembahasan fans ilmu yang secara umum bercorak pembahasan filsafat. $^{25}$ Penafsiran alQur'an sangat dinamis dan para mufassir al-Qur'an selalu berdialektika

24 Muhammad Husain Tabataba'i. (2002). al-'Aqaidah al-Islamiyyah. Lebanon: Beirut, hlm. 6.

25 Muhammad Husain Tabataba'i. (2002). al-'Aqaidah al-Islamiyyah. Lebanon: Beirut, hlm.7. 
dengan diri, perubahan dan tantangan yang dihadapinya. Secara singkat, dalam pembahasan tafsir di dalam tafsir al-Mizan, Tabataba'i merekam corak dan warna perkembangan tafsir baik dari kalangan Sunni maupun Syiah sendiri.

Tabataba'i menyatakan bahwa, yang dikehendaki dibalik apa yang dibaca serta dipahami dari ayat-ayat alQur'an adalah ada suatu perkara yang memposisikan al-Qur'an seperti ruh bagi jasad. ${ }^{26}$ Yakni, al-Qur'an memiliki makna lahir dan makna batin. Kedua makna tersebut menurutnya tidak saling menafikan. Pengetahuan mengenai keduanya sangat tergantung pada manusia sendiri, sejauh dan sebesar apa keterkaitannya kepada halhal yang bersifat spiritual dan material. Seperti saat beliau menafsirkan QS al'Imran ayat $92:{ }^{27}$

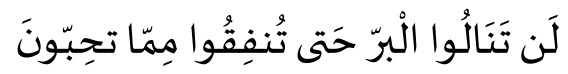

Maksud dari nail (memperoleh) adalah sampai, sedangkan al-birr (kebaikan) adalah rasa lapang dalam melakukan perbuatan yang baik. Dan

${ }^{26}$ Muhammad Husain Tabataba'i. hlm. 8 Muhammad Husain Tabataba'i. (1998). al-Mizan fi Tafsir al-Qur'an. Lebanon: Beirut, hlm. 394. amal baik ini sifatnya umum, baik berupa amaliyah hati seperti keyakinan kepada Allah, niat dan sebagainya, maupun amaliyah dhohir, seperti ibadah sholat kepada Allah, infaq di jalan Allah, dan sebagainya. Tabataba'i pada penjelasan ini memberikan maksud pada makna batinnya ayat bahwa menginfakkan harta benda yang disenangi di jalan Allah swt merupakan salah satu rukun untuk memperoleh albirr (kebaikan secara umum). ${ }^{28}$

\section{F. Latar Belakang Penulisan Kitab al-Mizan fi Tafsir al-Qur'an.}

Tafsir al-Qur'an yang disusun oleh Tabataba'i dikenal dengan alMizan yang berarti timbangan, keseimbangan atau moderasi. Sejak awal, tafsir ini didedikasikan untuk memberi pemahaman al-Qur'an kepada sejumlah muridnya yang hadir di majlis kajiannya. Setelah menetap di Qum, tepatnya pada $1375 \mathrm{H}$ atau $1956 \mathrm{M}$, juz pertama tafsir al-mizan selesai

28 Makna al-birr oleh sebagian ulama memiliki arti menginfakkan dari harta yang disenangi, pendapat lain menyatakan bahwa albirr sebagaimana makna dhohirnya lafat tersebut adalah kelapangan dalam kebaikan, pendapat lain mengemukakan bahwa al-birr merupakan ihsannya Allah dan kenikmatanNya yang dianugrahkan kepada manusia, dan pendapat lain menyatakan bahwa al-birr adalah surga. Lihat Muhammad Husain Tabataba'i. (1998). al-Mizan fi Tafsir al-Qur'an. Lebanon: Beirut, hlm. 395. 
disusun. ${ }^{29}$ Kajian al-Qur'an berlangsung bersama dengan kajian filsafat, sehingga tafsir al-mizan sangat kental nuansa filsafatnya. Hal ini bukan suatu kebetulan, karena sebagaimana dijelaskan sebelumnya, di dunia Syiah terdapat tradisi menggabungkan filsafat dengan tafsir al-Qur'an. ${ }^{30}$ Tafsir alMizan selesai ditulis pada 23 Ramadhan $1392 \mathrm{H}$ atau bertepatan dengan 1973 M hingga mencapai 20 juz atau sekitar 8041 halaman, dengan ratarata massing-masing juz 465 halaman. ${ }^{31}$

Penamaan kitab tafsirnya ini dengan nama tafsir al-Mizan, sebagaimana diungkapkan dalam muqadimah, bahwa di dalam kitab tafsir ini beliau Tabataba'i memperlihatkan dari berbagai pendapat serta pemaparannya para mufassir dan selainnya terkait penjelasan-penjelasan terhadap ayat-ayat al-Qur'an. Sehingga uraian yang beliau paparkan di dalam kitabnya terkadang terlihat seperti suatu perdebatan, baik dari sisi pendapat para mufassir maupun

\footnotetext{
29 Muhammad Husain Tabataba'i. (1998). al-Mizan fi Tafsir al-Qur'an. Lebanon: Beirut, hlm. Z.

30 Waryono Abdul Ghafur, Millah Ibrahim dalam Al-Mizan, hlm. 89

31 Muhammad Husain Tabataba'i. (1998). al-Mizan fi Tafsir al-Qur'an. juz 1, Lebanon: Beirut, hlm. Z.
}

lainnya, untuk diambil hasil yang sesuai sebagaimana yang di maksud oleh ayatayat al-Qur'an dan meninggalkan sebagian pendapat yang lain. ${ }^{32}$ Seperti saat beliau menjelaskan pendapat dari para mufassir terkait penafsiran ayat Q.S. Ali-Imran Ayat 19: ${ }^{33}$

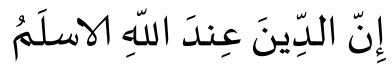

Terkait penjelasan pendapat tentang ayat ini, Tabataba'i menukil dari tafsir al-'Iyasyi dari riwayat Muhammad bin Muslim, bahwa yang di maksud dari lafat ayat ini adalah setiap agama yang di dalamnya ada keimanan kepada Allah. Sedangkan menurut pendapat Ibnu Syahr dari al-Baqir a.s bahwa yang dimaksud dari lafat ayat ini adalah memasrahkan hak wilayah (kekholifahan) terhadap Ali bin Abi Thalib. Kemudian dari pendapat Ali bin Abi Thalib bahwa Islam adalah taslim (memasrahkan), taslim adalah yakin, yakin adalah membenarkan, membenarkan adalah mengakui, mengakui adalah menjalankan, menjalankan adalah mengamalkan, yakni seorang mukmin memilih agama

${ }^{32}$ Lihat Muhammad Husain Tabataba'i. (1998). al-Mizan fi Tafsir al-Qur'an. juz 1, Lebanon: Beirut, hlm. $Z$.

${ }^{33}$ Lihat Muhammad Husain Tabataba'i. (1998). al-Mizan fi Tafsir al-Qur'an. juz 3, Lebanon: Beirut, hlm. 146. 
dari Allah, dan ia mengetahui bahwa keimanannya itu ada disetiap amaliyahnya, dan setiap orang kafir tau bahwa kekufurannya ada di dalam pengingkarannya. ${ }^{34}$

Kemudian setelah pemaparan dari pendapat ini, Tabataba'i mengutarakan pendapat bahwa, pendapat yang diutarakan oleh Ali bin Abi Thalib terkait penisbatan Islam sebagai agama yang benar dari sisi lafdiyah maupun ma'nawiyahnya, sekaligus penamaan Islam ini sebagai nama agama yang haq adalah karna pengakuannya manusia atas kekuasaan Allah, serta mengakui bahwa seluruh jiwa dan segala amal perbuatan manusia ini di bawah perintah dan kehendak Allah. ${ }^{35}$

Dengan demikian, tafsir ini diberi nama dengan al-Mizan seolah-olah Tabataba'i ingin menjadikan tafsirnya sebagai timbangan keseimbangan yang cemerlang guna memberikan pendapat yang kuat dan berimbang dalam menyelesaikan persoalan yang dialami dan dihadapi oleh umat Islam dengan mengutamakan penafsiran al-Qur'an dengan al-Qur'an dibanding harus

${ }^{34}$ Lihat Muhammad Husain Tabataba'i. (1998). al-Mizan fi Tafsir al-Qur'an, juz 3, Lebanon: Beirut, hlm. 146.

${ }^{35}$ Lihat Muhammad Husain Tabataba'i. hlm. 147. terikat dan fanatik dengan teori tertentu. Pada saat membicarakan suatu masalah, beliau lebih banyak merujuk kepada sumber penafsiran kepada ayatayat al-Qur'an dan menyimpulkan maksudnya dari merujuk pendapat yang dikemukakan mufasir dan pengkaji alQur'an.

\section{G. Sistematika serta Metodologi Kitab al-Mizan fi Tafsir al- Qur'an.}

Keberadaan sistematika tafsir alMizan dimulai dengan mukaddimah atau pengantar meliputi pernyataan pentahqiq dan pernyataan beliau sendiri (Tabataba'i). Dalam mukaddimahnya, beliau secara singkat memperkenalkan cara-cara yang ditempuh dalam menjelaskan makna-makna al-Qur'an. Kemudian melangkah menjelaskan corak penafsiran ulama terhadap alQur'an yang diantaranya terdiri dari: pertama, Ulama hadis (muhaddisin), mereka mencukupkan diri pada penafsiran berdasarkan riwayat dari ulama-ulama salaf, sahabat, dan tabiin. Mereka tidak menjelaskan makna ayat yang tidak dijelaskan oleh para sahabat, ulama salaf serta tabiin, ${ }^{36}$ kedua, Para

\footnotetext{
36 Muhammad Husain Tabataba'i. (1998). al-Mizan fi Tafsir al-Qur'an. juz 1, Lebanon: Beirut, hlm. 9.
} 
teolog (al-mutakallimin). Mereka menggunakan berbagai macam pendapat mazhab dengan segala perbedaannya. Pendapat-pendapat yang sesuai diambil, sedangkan ayat yang tidak sesuai dengan mahzabnya, diinterpretasi sesuai dengan batas-batas kewenangan yang ada dalam mahzab, ${ }^{37}$ ketiga, Para filosof (al-falasifah). Mereka mentakwilkan ayat-ayat yang secara lahiriah berbeda untuk disesuaikan dengan pendapatnya, dan keempat, Para sufi (al-mutasshawifah). Mereka menekankan pada aspek batiniyyah penciptaan dan perhatiannya pada ayat-ayat kesejatian semata. ${ }^{38}$

Dalam mukaddimah ini juga sebagaimana dijelaskan oleh al-nasyir kitab al-Mizan, bahwa manhaj yang dipergunakan oleh Tabataba'i dalam menafsirkan ayat-ayat al-Qur'an dalam tafsir al-Mizan ini di antaranya adalah sebagai berikut: ${ }^{39}$ pertama, Tabataba'i dalam menjelaskan tafsirnya menggunakan data yang begitu banyak, baik dari kalangan para mufassir, ahli hadis, ahli sejarah, filosof maupun yang lainnya. ${ }^{40}$ Kedua, Menjelaskan tujuan

\footnotetext{
${ }^{37}$ Muhammad Husain Tabataba'i. hlm, 9.

${ }^{38}$ Muhammad Husain Tabataba'i. hlm, 10.

39 Muhammad Husain Tabataba'i. hlm, Za-Ja.

${ }^{40}$ Muhammad Husain Tabataba'i. hlm. 16.
}

dari surat maupun ayat yang akan beliau tafsirkan sebelum melangkah pada pembahasan penafsiran ayat-ayat dari surat yang akan dijelaskan oleh beliau. Seperti ungkapan beliau saat mau menafsirkan surat Ali-'Imran, beliau mengungkapkan bahwa tujuan dari surat ini di antaranya adalah mengajak kaum mukminin untuk mentauhidkan Allah, sabar dan tetap tegar saat menghadapi kesulitan. ${ }^{41}$ Ketiga, Berpegangan dengan dasar prinsip-prinsip dalam membuka maknamakna ayat al-Qur'an dengan cara merujuk pada pendapat para ahli tafsir dengan cara menghadirkan pendapat atas penafsirannya ayat oleh para mufassir maupun ahli sunnah, yang kemudian menyatakan menerima atau menolak dari pendapat yang dinyatakan oleh para ahli tafsir, sekaligus menjelaskan hubungan antar ayat satu dengan yang lainnya. Seperti saat beliau menafsirkan ayat 130-138 pada Q.S. Ali-'Imran dengan menyatakan bahwa ayat-ayat ini mengajak untuk berbuat baik serta mencegah dari perbuatan buruk, dan ayat-ayat memiliki hubungan dengan ayat

${ }^{41}$ Lihat Muhammad Husain Tabataba'i. (1998). al-Mizan fi Tafsir al-Qur'an. juz 3, Lebanon: Beirut, hlm. 6. 
sebelum ataupun dengan ayat sesudahnya yang menjelaskan tentang kisah perang Uhud. $^{42}$ Keempat, Menafsirkan suatu ayat dengan jalan merenungkan dan mengkaji ayat itu dan ayat lain yang memiliki keterkaitan, dan dengan bantuan hadis-hadis. Dan saat menyebutkan sanadnya, beliau tidak mentebutkan garis sanad secara sempurna, namun secara umum cukup hanya menyebutkan dari sang pemilik kitab hadis tersebut. Kelima, Mengungkapkan asbabun nuzul ayat untuk menjelaskan nas-nas al-Qur'an terkait dengan masalah hukum. Dan juga mencantumkan qaul-qaulnya para sahabat maupun tabi'in terkait penafsiran ayat yang menjadi pembahasan beliau. Keenam, Sangat mauquf (berhenti) dari periwayatan israiliyat. Sekaligus mengingatkan bahwa banyak dari kalangan para ahli tafsir menempatkan periwayatan israiliyyat ini yang menjadikan 'illah (kecacatan) dalam tabiat dari kisah yang ada pada penafsiran ayat tersebut. ${ }^{43}$ Ketujuh, Menguraiakan ayat dari aspek bahasa, i'rab maupun

42 Lihat Lihat Muhammad Husain Tabataba'i. (1998). al-Mizan fi Tafsir alQur'an, juz 4, Lebanon: Beirut, hlm. 19.

${ }^{43}$ Lihat Muhammad Husain Tabataba'i. (1998). al-Mizan fi Tafsir al-Qur'an. juz 1, Lebanon: Beirut, hlm. y balaghoh dari ayat-ayat yang akan beliau jelasskan. Seperti saat beliau menafsirkan ayat:

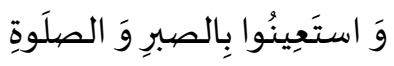

Maksud dari isti'anah (meminta tolong) yakni, memohon pertolongan kepada Allah, karna pada hakikatnya tidak ada pertolongan kecuali pertolongan Allah. Memohon pertolongan terhadap hal-hal yang menjadi tujuan manusia akan menjadi lebih kuat dengan jalan berpegang teguh, istiqomah, dan berusaha untuk wusul (sampai) kepada Allah swt, dan usaha ini tercakup di dalam sholat dan sabar, karna kedua hal ini adalah sebaik-baiknya sebab untuk bisa menggapai apa yang menjadi tujuan manusia. ${ }^{44}$ Kedelapan, Menjelaskan makna batin dan makna dhohimya ayat serta hakikatnya syariat Islam. Seperti ungkapan beliau terkait penafsiran lafat libas dalam QS. AlBaqarah ayat 187 , bahwa makna dhohir dari lafat libas ini adalah kemakrufan, yakni sesuatu yang dipergunakan sebagai tutup aurat badannya manusia. Sedangkan makna batimnya adalah

44 Lebih lengkapnya pembahasan penafsiran Tabataba'i mengenai pengertian isti'anah lihat saat beliau menafsirkan ayat 4546 QS al-Baqarah. Muhammad Husain Tabataba'i. (1998). al-Mizan fi Tafsir alQur'an, juz 1, Lebanon: Beirut, hlm. 152. 
bahwa setiap dari pasangan suami istri masing-masing adalah pakaian yang menutupi serta menjaga kejelekan, aib, serta auratnya diantara satu sama lain. ${ }^{45}$ Kesembilan, Ketika ayat al-Qur'an itu mengabarkan tentang hal-hal yang ghoib, seperti 'arsy, qolam, lauhil mahfud, maupun yang lainnya, beliau menempuh jalan yang berbeda dari kalangan ulama salaf saat menyatakan bahwa hal yang ghoib ini tidak bisa dijangkau oleh nalar manusia untuk mentakwil makna-makna ayat terkait pemberitaan alam ghoib kecuali Allah. Dalam hal ini, beliau berpendapat bahwa hakikat atas penafsiran ayat-ayat yang demikian ini dengan cara melihat pada apa yang telah diberikan oleh lafat itu dari segi pengertian dan bahasanya. $^{46}$ Dan kesepuluh, Meringkas penafsiran ayat yang terkait pada pembahasan hukumhukum fikih. Dalam hal ini beliau hanya menjelaskan secara garis besarnya saja dari faidah hukum fiqih tersebut. ${ }^{47}$

45 Muhammad Husain Tabataba'i. (1998). al-Mizan fi Tafsir al-Qur'an, juz 1, Lebanon: Beirut, hlm. 46.

46 Menurut beliau, takwil merupakan langkah untuk mengetahui makna hakikat dari apa yang telah disandarkan oleh ayat-ayat alQur'an yang meliputinya. Lihat Muhammad Husain Tabataba'i. (1998). al-Mizan fi Tafsir al-Qur'an, juz 1, Lebanon: Beirut, hlm. k

47 Muhammad Husain Tabataba'i. (1998). al-Mizan fi Tafsir al-Qur'an, juz 1, Lebanon: Beirut, hlm. 17.
Setelah mukaddimah, Tabataba'i melanjutkan dengan menafsirkan ayatayat al-Qur'an sesuai dengan urutan mushaf yang dikenal, yakni mulai dari surat al-Fatihah sampai dengan surat alNas secara utuh. Setiap memulai tafsir atas surat al-Qur' an, beliau memulainya dengan menguraikan tujuan esensi dari surat tersebut dan tujuan-tujuan yang dijelaskan oleh ayat-ayat dari surat tersebut. Dalam tafsirnya, beliau juga menjelaskan makna lafat atau ayat yang memiliki sisi makna berbilang sejauh dapat membantu untuk mengungkap maksud ayat dengan berbegang pada beberapa kamus bahasa dan tafsir. Di antaranya adalah al-Mufradat fi Gharib al-Qur'an karya Raghib al-Ashfihani dan Lisan Al-'Arab karya Ibnu Mandhur. Dalam menjelaskan tafsirnya, beliau banyak menggunakan pendapat para mufassir, riwayat, dan literatur. Beberapa pendapat dan riwayat tersebut diungkap untuk kemudian dinilai kualitasnya dan dipilih yang menurutnya kuat atau sahih untuk menjelaskan sebuah ayat dan kemudian diakhiri dengan kesimpulan. ${ }^{48}$

48 Muhammad Husain Tabataba'i. (1998). al-Mizan fi Tafsir al-Qur'an. juz 1, Lebanon: Beirut, hlm. 17. 
Secara sistematis, urutan penulisan tafsir al-Mizan adalah nama surat, status surat dan jumlah ayat, ayat atau kelompok ayat al-Qur'an yang akan ditafsirkan baru kemudian penjelasan. Beliau tidak menggunakan kata atau istilah tafsir ayat atau surat, tapi bayan. Meskipun keduanya berbeda dalam arti, namun dari caranya menjelaskan al-Qur'an tampak bahwa bayan yang dimaksdukan adalah tafsir ayat sesuai dengan bunyi teks yang akan dibahas. Dalam penjelasan (bayan)nya terhadap ayat, beliau mencantumkan ayat lain dengan ayat yang ditafsirkan (tafsir qur'an bi qur'an), dengan terlebih dahulu melakukan analisa bahasa (bila diperlukan dan dapat membantu memahami ayat) dengan berpedoman pada kaedah-kaedah bahasa dari aspek nahwu, sharaf, serta balaghah (analisa gramatika dan sastra) terlebih bila kalimat tersebut memiliki i'rab, kemudian diikuti dengan penjelasan makna kalimat denngan mengutip syair, membeberkan ragam qiraah untuk menerangkan perbedaan maknanya, tujuan surat dan ayat, serta menyertakan asbabun nuzul nya bila ada yang didasarkan pada hadis yang shohih. Bayan inilah yang selalu ada dalam tafsirnya. ${ }^{49}$ Kemudian setalah bayan, diikuti dengan menjelaskan ayat dengan riwayat, dan juga menjelaskan ayat dengan berbagai pendekatan, yaitu filsafat (falsafy), sosiologis (ijtima'i), historis (tarikhy), ilmiah ( 'ilmy), ilmiah dan etika ('ilmy wa akhlaqy), ilmiah dan filosofis ('ilmy wa falsafy), dan rasional dan qur'ani ( 'aqly wa qur'any). Dalam penjelasannya dengan riwayat terkadang beliau menyusulnya dengan riwayat yang lain, begitu juga terkadang menjelaskan secara filosofis dan ilmiyyah yang lain dari suatu ayat. Dengan demikian, berdasarkan uraian diatas, keberadaan tafsir al-Mizan dapat dikategorikan sebagai tafsir bi alra'yi dengan metode tahlily dan corak falsafy. $^{50}$

49 Waryono Abdul Ghafur, Millah Ibrahim dalam Al-Mizan, hlm. 10. Juga lihat Seperti saat menjelaskan penafsiran QS al'Imran ayat 26-27. Lihat Muhammad Husain Tabataba'i. (1998). al-Mizan fi Tafsir alQur'an. juz 3, Lebanon: Beirut, hlm. 148-173.

${ }^{50}$ Tafsir bi al-ra'yi adalah tafsir yang bersumber dari ijtihad seorang mufasir. Dengan kata lain tafsir yang bukan berasal dari riwayat, tapi dari kreasi intelektual seorang mufasir. Sedangkan metode tahlily merupakan metode tafsir al-Qur'an yang memaparkan segala aspek yang terkandung didalam al-Qur'an yang ditafsirkan serta menerangkan makna-makna yang tercakup didalamnya, sesui dengan keahlian dan kecenderungan mufassir yang menafsirkan ayat-ayat tersebut. Sedangankan corak falsafy adalah upaya penafsiran al-Qur'an yang dikaitkan dengan persoalan-persoalan filsafat, atau bisa juga diartikan dengan penafsiran ayat-ayat al-Qur'an dengan 


\section{H. Sumber Penafsiran}

Beberapa literatur yang digunakan Tabataba'i dalam menyusun tafsirnya mencapai 135 judul meliputi buku, kamus, majalah dan koran dan telah dikelompokkan oleh al-Usiy menjadi beberapa kategori, ${ }^{51}$ yaitu: pertama, tafsir. Literatur tafsir yang beliau gunakan meliputi tafsir klasik hingga modern dari berbagai aliran, seperti tanwirul Miqbas yang dinisbatkan kepada Ibnu Abbas, alKasysyaf karyanya al-Zamakhsari, dan kitab-kitab tafsir lainnya dari berbagai aliran. Kedua, kamus bahasa seperti alShihah karya Ismail bin Hammad alJauhari, Lisan al-'Arab karya Ibnu Mandhur, dan kamus-kamus bahasa lainnya. Ketiga, kitab-kitab hadis dan rijalul hadis dari kalangan Sunni dan Syiah seperti, Tahdzibut Tahdzib karya Ibnu Hajar al-`Asqalani, al-Ihtijaj karya Tibrisy, dan lain-lain. Keempat, kitab-

menggunakan teori-teori filsafat. Lihat Irhas. (2015). "Penerapan Tafsir al-Qur'an bi alQur'an (Studi Atas Kitab Tafsir al-Mizan fi Tafsir al-Qur'an Karya Muhammad Husain alThabathaba'i)", Jurnal Ushuluddin Vol. 24, No. 2, Juli-Desember 2016, hln. 151. Abdul Syukur, "Mengenal Corak Tafsir al-Qur'an", ElFurqonia, Vol. 01, No. 01, hlm. 94.

51 Yusno Abdullah Otta, "Dimensidimensi Mistik Tafsir al-Mizan (Studi Atas Pemikiran Tabataba'i dalam Tafsir al-Mizan)", Jurnal IAN Manado, hlm. 25-17. Juga lihat Waryono Abdul Ghafur, Millah Ibrahim dalam Al-Mizan, hlm. 98-99. kitab Suci seperti Injil (perjanjian Lama dan Baru), Avesta (kitab suci agama Zoroaster), Risalah Paulus, Taurat, Sawa'i (salah satu kitab suci kristen Ortodok Romawi), dan Weda. Kelima, buku-buku sejarah baik yang ditulis oleh orang Islam maupun non Islam, seperti Tarikh al-Tabari karya Ibnu jarir al-Tabari, Tarikh Tamadun Islam karya Kristor Liang, lain-lainnya. Keenam, pengetahuan umum, seperti al-Umm karya al-Syafi'i, Ihya Ulumuddin karya al-Ghazali, dan kitab-kitab lainnya. Dan ketujuh adalah koran dan majalah yang dikutib Tabataba'i, terutama mengenai beberapa peristiwa dan informasi ilmiah, seperti koran Ithila'iyyah al-Iraniyyah, dan lain sebagainya.

\section{Kelebihan dan Kekurangan tafsir al-Mizan}

Sebagaimana diketahui bahwa setiap karya tulis pasti memiliki kelebihan maupun kekurangan sesuai dengan fans ilmu yang dibahas di dalam kitab tersebut. Mengenai hal kelebihan dan kekurangan dari kirab tafsir alMizan yaitu:

1. Kelebihan kitab Tafsir al-Mizan a. Dalam menafsirkan alQur'an, Tabataba'i memiliki disiplin ilmu yang begitu 
banyak mulai dari yang berhubungan dengan agama sampai dengan ilmu-ilmu umum maka dalam penafsirannya banyak ilmuilmu yang dapat menunjang dalam penafsiran ayat tersebut terhadap Al-Qur'an itu sendiri

b. Beliau begitu teliti dalam menukil riwayat baik itu yang dinukil dari Rasulullah, Sahabat, maupun dikalangan tabi'in itu sendiri.

c. Beliau hanya mengambil sesuatu yang bermanfaat saja dalam kitab-kitab yang lain.

d. Melakukan tarjih atau mengungkapkan posisi pendapat beliau setiap selesai penafsiran ayat dengan menyebutkan alasanalasannya

e. Walaupun beliau termasuk ulama Syi'ah akan tetapi penafsirannya untuk memperkuat posisi syi'ah itu tidak terlalu karena ia juga membandingbandingkan dengan Sunni.

2. Adapun kelemahan Tafsir alMizan

a. Tidak menyebutkan sanad hadis secara sempurna akan tetapi cukup menyebut sumber pertamanya meskipun terkadang menyebutnya. Sedang hadis yang terkait dengan fadhilah-fadhilah surah tidak disebutkan.

b. Fanatik terhadap aqidah Syi'ah

c. Lebih banyak merujuk kepada pendapat dan kitabkitab para ulama Syiah. Wallahua'lam.

\section{J. Contoh Penafsiran}

Dalam pembahasan contoh penafsiran dari tafsir al-Mizan, sebagaimana sebagian kecil telah penulis sebutkan di atas, disini penulis secara sederhana dan singkat mencoba menyuguhkan tema ayat yang tercantum dalam QS. Al-Baqarah ayat 213, yakni terkait pembahasan risalah kenabian:

$$
\begin{aligned}
& \text { كانَ النّاس أُمّلةً وَحِدَةً فَبَعَث اللَُّ } \\
& \text { النّبِيِينَ مُبَشَرِينَ وَ مُنِِِِْينَ وَ أَنَزَلَ } \\
& \text { مَحَهُمُ الْكِتَبَ بِالْحَقِّ لِيَحْكُمَ بَينَ } \\
& \text { النّاسِ فِيمَا اخْتَلَفُوا فِيِِِ وَ مَا } \\
& \text { اخْتَفَف فِيهِ إِلا الَّذِينَ أُوتُوهُ مِن }
\end{aligned}
$$

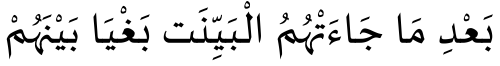

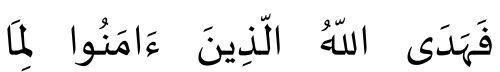

$$
\begin{aligned}
& \text { اخْتَلَفُوا فِيِِِ مِنَ الْحَقِّ بِإِذنِِهِ وَ } \\
& \text { اللهُ يَهْدِى مَن يَشَاءُ إلِى صِرَطِ } \\
& \text { مَستَتِيمِمِ }
\end{aligned}
$$


Pada penjelasan al-bayan: ${ }^{52}$ Ayat di atas menjelaskan mengenai sebab disyariatkannya pokok dasar agama dan pembebanan terhadap manusia agar kembali kepada agama tersebut serta sebab terjadinya perbedaan dalam masalah agama. Pada dasarnya manusia berada dalam golongan satu umat atau satu bangsa, kemudian muncul perbedaanperbedaan berdasarkan fitrah dalam dirinya untuk memperoleh keuntungan maupun kenikmatan hidup. Adanya perbedaanperbedaan ini menuntut agar diletakkan undang-undang hukum dengan diutusnya para nabi untuk menghilangkan perbedaan dan pertengkaran dengan berlandaskan agama, dan disertai dengan dakwah dan peringatan tentang adanya pahala dan siksa, serta memperbaiki amal buruk dengan cara ibadah melalui petunjuk para nabi yang diutus oleh Allah. Pokok dasar agama ini adalah agama ilahi yang merupakan satu-satunya sebab agar manusia memperoleh kebahagiaan, memperbaiki

${ }^{52}$ Lihat Muhammad Husain Tabataba'i. (1998). al-Mizan fi Tafsir al-Qur'an. juz 2, Lebanon: Beirut, hlm. 114. persoalan hidupnya, serta memperbaiki naluri fitrahnya agar manusia hidup dalam satu kehidupan sosial maupun keagamaan.

Pada Perbahasan dari periwayatan: Menurut riwayat Imam alBaqir dalam kitab al-Majmu' bahwa manusia sebelum masa Nabi Nuh berada dalam satu golongan umat serta dalam fitrah Allah. Dan dalam tafsir al'Iyasy dari riwayat Imam al-Shodiq bahwa ayat ini adalah menceritakan tentang umat sebelum nabi Nuh as. ${ }^{53}$ Pembahasan Filsafat: Meskipun pembahasan mengenai risalah kenabian dari segi penyampaian hukum-hukum serta aturan-aturan syariat agama adalah pembahasan yang bersifat kalamiyyah, namun jika dipandang dari sisi lain juga terdapat pembahasan filsafat terkait dengan risalah kenabian ini. Yakni, ajakan untuk berada dalam garis agama dengan cara memberikan kabar gembira maupun menakut-nakuti adalah agar menjadi obat bagi setiap orang mukmin untuk menyempurnakan hidup dalam meraih kebahagiannya melalui jalan agama. Sebab, setiap manusia yang dibekali dengan akal

${ }^{53}$ Lihat Muhammad Husain Tabataba'i. (1998). al-Mizan fi Tafsir al-Qur'an, juz 2, Lebanon: Beirut, hlm. 146. 
serta hawa nafsu secara umum menjadikannya untuk berusaha meraih jalan kesempurnaan dalam hal apapun. Dengan adanya kemauan ini akan menjadikan manusia itu untuk merubah kondisinya dengan kekuatan-kekuatan dari hasrat tersebut dengan cara berbuat pada apa yang menjadi dari tujuan jiwa manusia tersebut dengan berpijak pada jalan agama untuk membedakan mana yang baik, mana yang buruk. Melalui usaha ini, akan terpancar keyakinan tentang adanya kebaikan dan keburukan, ketakutan dan harapan, keinginan pada hal yang bermangfaat, ketakutan dari kerugian, dan lain sebagaianya. Atas pancaran inilah risalah kenabian sangat berperan untuk mengembalikan dan menyeimbangkan hasrat-hasrat tersebut manusia berjalan pada jalan agama untuk meraih kebahagiaan yang haqiqi dari apa yang menjadi tujuannya. ${ }^{54}$

Penjelasan yang beliau suguhkan dalam menafsirkan ayat di atas sangat panjang dan luas dengan aneka ragam pembahasan. Beliau menjelaskan pokok risalah kenabian dari semua aspeknya, baik dari sisi risalah penyampaiannya

${ }^{54}$ Lihat Muhammad Husain Tabataba'i. (1998). al-Mizan fi Tafsir al-Qur'an, juz 2, Lebanon: Beirut, hlm. 151. maupun pengukuhan risalah tersebut dengan kemukjizatan.

\section{K. Kesimpulan}

Dari uraian pembahasan di atas, maka dapat ditarik kesimpulan sebagai berikut:

1. Tabataba'i memiliki nama lengkap Muhammad Husain Tabataba'i. Beliau lahir pada skhir $1321 \mathrm{H}$, tepatnya pada 29 Dzulhijjah $1321 \quad \mathrm{H}$ atau bertepatan dengan $1903 \mathrm{M}$ di desa Shadegan, Propinsi Tibriz atau Tabriz.

2. Tafsir al-Mizan yang pada awalnya merupakan pengajian kepada para muridnya dan disusun dalam jangka waktu yang cukup lama dan menjadi salah satu tafsir terbaik Syi'ah. Tafsir tersebut berjumlah 20 jilid dan berkarakter Syi'ah.

3. Penafsiran kitab tafsir al-Mizan yakni dengan cara menjelaskan ayat dengan ayat, riwayat. kemudian beliau juga menjelaskan ayat dengan berbagai pendekatan. Beliau juga mengklasifikasi ayat-ayat sesuai dengan topiknya kemudian melakukan pembahasan secara kelompok pula, mulai dari penjelasan umum, seperti nahwu, maksud dan sejenisnya dengan menggunakan ayat-ayat yang semakna, kemudian menambahkan pembahasan riwayat, bahkan ilmiah dan 
filsafat dikelompokkan tersendiri.

4. Tafsir al-Mizan merupakan karya Tabataba'i yang paling fenomenal, dari semua tulisan yang pernah dihasilkannya. Karya tafsir ini, pada kenyataannya, tidak bisa dilepaskan dari pemikiran penulisnya yang bercorak filosofis. Karena, sebagaimana telah diketahui, filsafat merupakan salah satu cabang ilmu yang tidak pernah mati di kalangan Syiah, dan selalu mengalami perkembangan hingga sekarang ini. Wallahua'lam

\section{Daftar Pustaka}

Abdul Ghafur, W. (2008). Millah Ibrahim dalam Al-Mizan fi tafsir al-Qur'an. Yogyakarta: Bidang Akademik.

Ayyub, M. (1991). Qur'an dan Para Penafsirnya. Jakarta: Pustaka Firdaus.

Irhas. (2016). Penerapan Tafsir alQur'an bi al-Qur'an (Studi Atas
Kitab Tafsir al-Mizan fi Tafsir al-Qur'an Karya Muhammad Husain al-Thabathaba'i. Jurnal Ushuluddin.

Otta, Y. A. (n.d.). Dimensi-dimensi Mistik Tafsir al-Mizan (Studi Atas Pemikiran Tabat $\}$ aba'i dalam Tafsir al-Mizan. Jurnal IAN Manado.

Syukur, A. (2015). Mengenal Corak Tafsir al-Qur'an. El-Furqonia.

Tabataba'i, M. H. (1987). Mengungkap Rahasia al-Qur'an. Bandung: Penerbit Mizan.

Tabataba'i, M. H. (1996). Inilah Islam; Upaya Memahami Seluruh Konsep Islam Secara Mudah. Bandung: Pustaka Hidayah.

Tabataba'i, M. H. (1998). al-Mizan fi Tafsir al-Qur'an. Lebanon: Beirut.

Tabataba'i, M. H. (2002). al-'Aqaidah al-Islamiyyah. Lebanon: Beirut.

Tabataba'i, M. H. (2006). Tafsir alBayan fi al-Muwafaqah baina al-Hadis wa al-Qur'an. Lebanon: Beirut. 


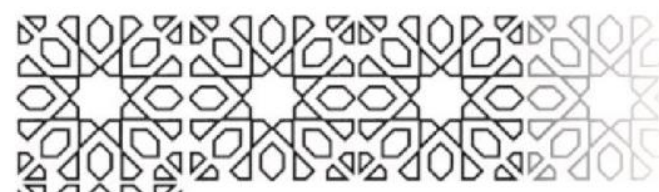

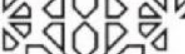

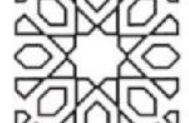

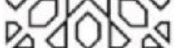

$\triangle 50 \nabla_{\Delta}$ 